INTERNATIONAL DESIGN CONFERENCE - DESIGN 2018

https://doi.org/10.21278/idc.2018.0191

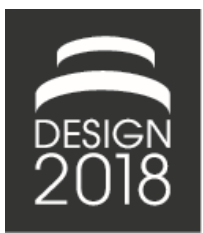

\title{
CONTENT AND FUNCTIONS OF AN INTERNET- BASED PLATFORM FOR SUPPORTING DEVELOPMENT OF ADDITIVELY MANUFACTURED PARTS
}

\author{
F. Weiss, D. Roth and H. Binz
}

\begin{abstract}
To enable efficient and effective development of additively manufactured parts, the development process can be supported by a tailored information platform. In this paper, an Internet-based information platform for this purpose is presented. A survey in an industrial environment with 35 participants was conducted to determine the beneficial functions and information on the platform. This paper presents the results of the survey and the realization of an information platform as a digital support tool for designing additively manufactured parts.
\end{abstract}

Keywords: additive manufacturing, design support system, 3D printing, design guidelines

\section{Introduction}

A design for additive manufacturing (DfAM) requires several kinds of information. During product development, the type of information required changes permanently in line with the iterative development process, an example of which is described in VDI 2221 (VDI, 1987). In this paper, an Internet-based platform offering fast access to the required information is presented. The objective of the platform is to enable designers to conduct focused development of additively manufactured (AM) products. Similar to other development processes, a DfAM not only includes a design for manufacturability, but also the optimization of functionality, the consideration of available materials, cost reduction and limitation through achievable precision, among other things. Taking full advantage of the unique capabilities of AM technologies is challenging for most designers as design rules or guidelines for conventional manufacturing are deeply entrenched in the minds of those designers (Tang and Zhao, 2016), even if a great deal of information required for developing AM products can be found in literature. Laverne et al. (2014) show that methodologies for early design stages are rarely supported by digital tools. In order to ensure high usability of the information system and speed up the development of additively manufactured parts, an Internet-based platform that offers the required information is presented in this paper. The underlying research question throughout this paper is as follows: "What information is needed to support design specifically for additively manufactured parts and how should the information be accessible?" The content of the platform was modified in accordance with a survey conducted in an industrial environment, and it is structured according to several development phases of an additively manufactured component. The results of the survey are presented in the following sections, as are the structure and features of the platform. 


\section{Method}

A literature review was undertaken to develop a digital tool for supporting the development of additively manufactured parts. Following this review, an online survey was conducted in an industrial environment.

\subsection{Content of the survey}

In order to answer the first part of the research question, a literature review was conducted to find studies providing information that should potentially be considered for integration into the support system. The literature review included established volumes such as (Gibson et al., 2015; Gebhardt and Hötter, 2016), in addition to various papers. A study that conclusively answers the first part of the research question could not be found, although several works highlighting different aspects of AM-specific development were identified. The following reviewed papers with a close relation to support in the development of additively manufactured products were found: Hague et al. (2005), Kirchner (2011), Vayre et al. (2012), Adam and Zimmer (2014), Laverne et al. (2014), Mellor et al. (2014), Ponche et al. (2014), Yang et al. (2015), acatech et al. (2016), Hällgren et al. (2016), Kumke et al. (2016), Leutenecker-Twelsiek et al. (2016), Tang and Zhao (2016), Thompson et al. (2016), Seepersad et al. (2017), Zhu et al. (2017). The relevant aspects of these papers were adapted to match the purpose of the survey. The survey was structured and the answer options were formulated in accordance with the results of the literature review.

\subsection{Boundary conditions of the survey}

The invitation to participate was issued through the mailing list of a large German industrial association and the mailing list of a German state agency containing persons interested in AM. 35 persons participated in the survey, which contained questions concerning general information about the participants, information required for a DfAM and requirements for the Internet-based platform which would ensure high usability. The participants originated from differently sized companies (Figure 1a). They were mostly male (see Figure 1b) and represent different hierarchical levels in the respective companies (Figure 1c).

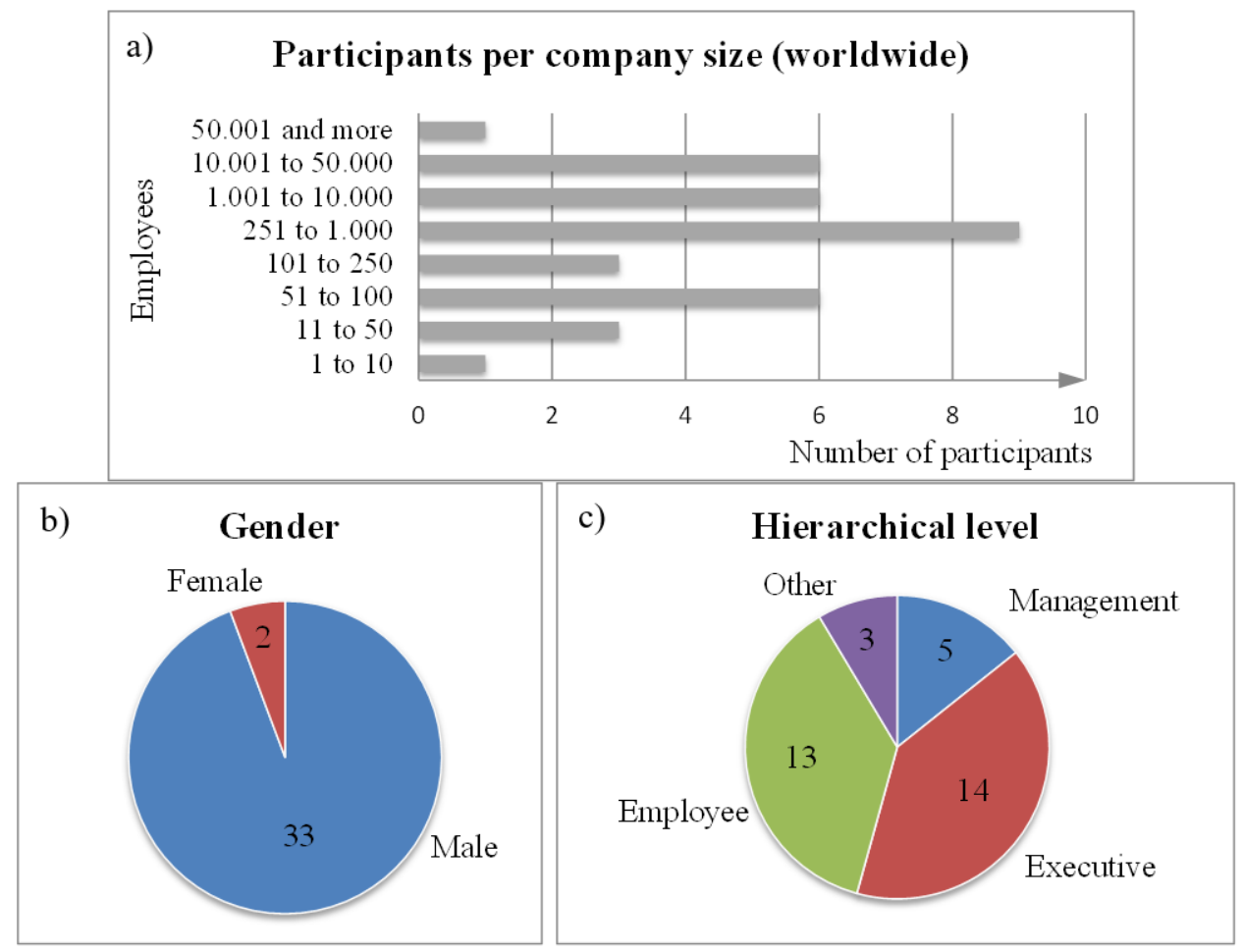

Figure 1. Company size, gender and hierarchical level of the participants 
The distribution list of the survey was composed in order to consult experienced product developers and designers on the topic of additive manufacturing. To assess the participants' AM expertise, their selfassessment was included in the questionnaire on a scale from 1 (no expertise) to 5 (expert). The result of this is shown in Figure 2. The data shows a weighting toward higher expertise and has a mean of 3.42. According to the number of 35 participants, the statistical power of the survey is limited. This is why a Kolmogorov-Smirnov test shows, that the data of the self-assessment features neither a Gaussian nor uniform distribution.

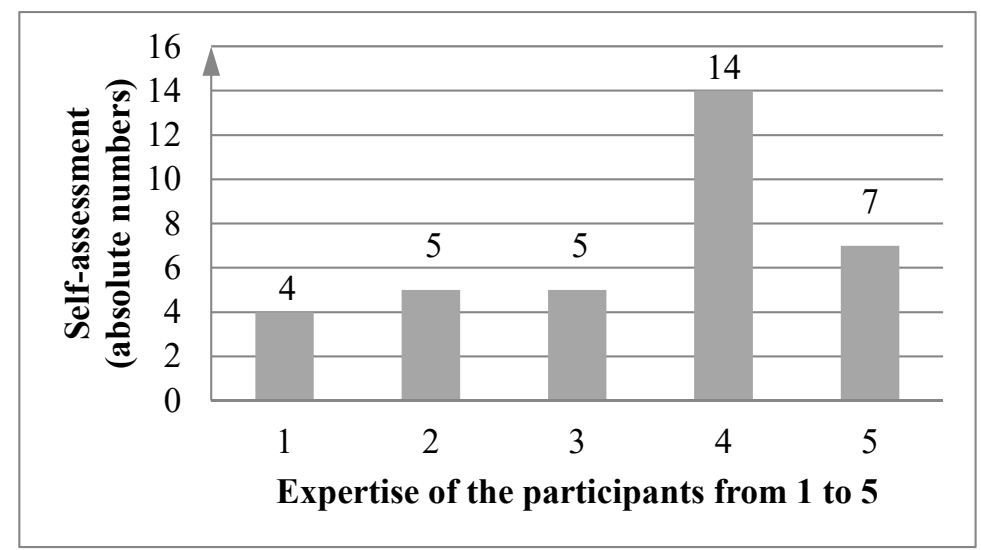

Figure 2. Self-assessment of participants' expertise

\section{Boundary conditions for the use of AM}

The boundary conditions of the use of AM technologies were queried in order to ascertain the context in which the developed Internet-based platform was to be used: The results are presented in this section. The results of the survey regarding the nature of the participants' occupation with AM are shown in Figure 3, which reveals that the participants mostly use AM in engineering design and the development of additively manufactured products. However, some of them also work in the fields of R\&D with a focus on improving AM manufacturing and related processes, and in providing the technologies as a service.

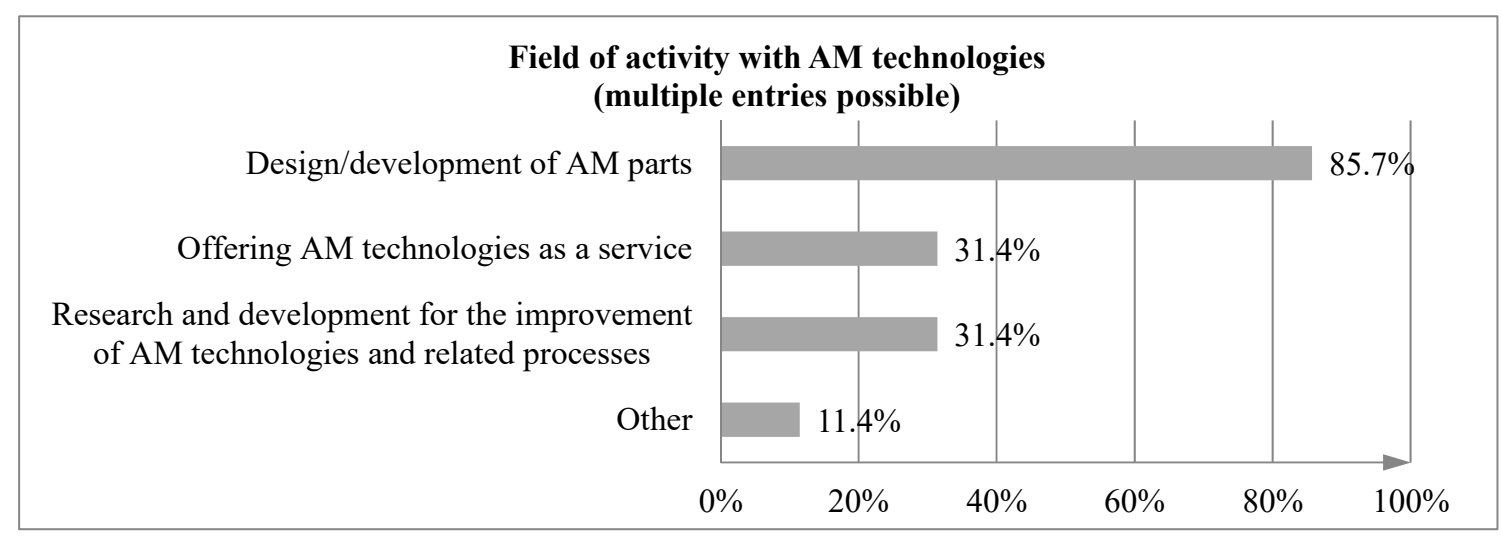

Figure 3. Nature of participants' occupation with AM

The areas of interest for the field of application of AM technologies are shown in Figure 4. The use of AM technologies was rated as being less interesting as the batch sizes increased. $85.7 \%$ of the participants are interested in the technology for use in prototyping. For producing end products, the interest in AM decreased as the batch size increased, from $74.3 \%$ with a batch size of 1 to $11.4 \%$ with batch sizes of more than 1000 units. Nonetheless, $45.7 \%$ of the participants are interested in the technologies for tooling and $37.1 \%$ in using AM as a bridge technology for manufacturing products with uncertain market prospects. 


\section{Areas of interest for the application of AM technologies}

(multiple entries possible)

Prototyping during development projects

Production of individualized products with batch size 1

Production of end products with small batch sizes $(<1000$ pcs.)

Production of tools

Bridging technology (for products with uncertain market prospects)

Production of moulds

Production of end products with large batch sizes $(>1000$ pcs.)

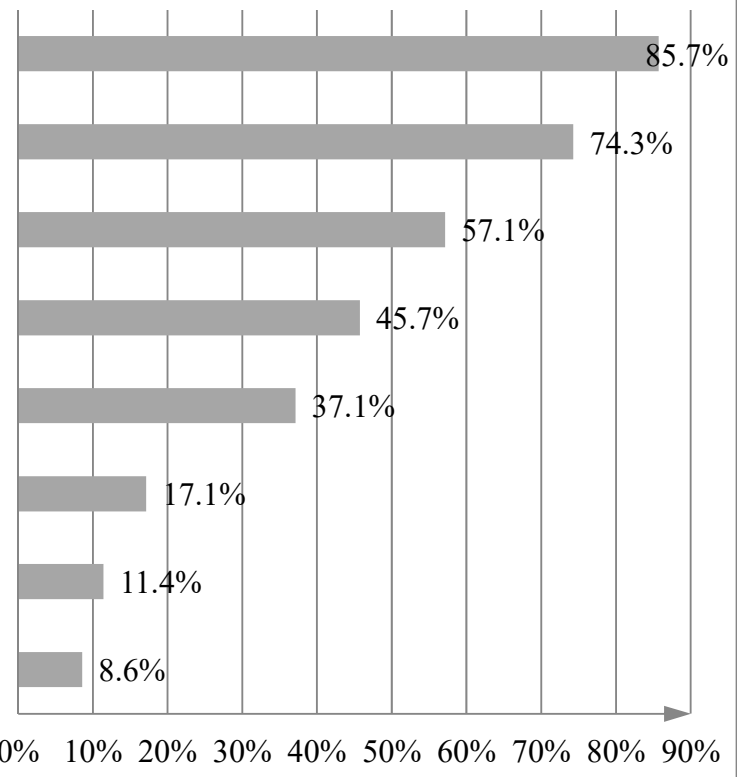

Figure 4. Reasons for the use of AM technologies

The result of the ranking of the most interesting AM technologies for the participants is shown in Figure 5. Laser sintering (LS) is of the most interest for the participants, followed by laser beam melting (LBM) and fused deposition modeling (FDM).

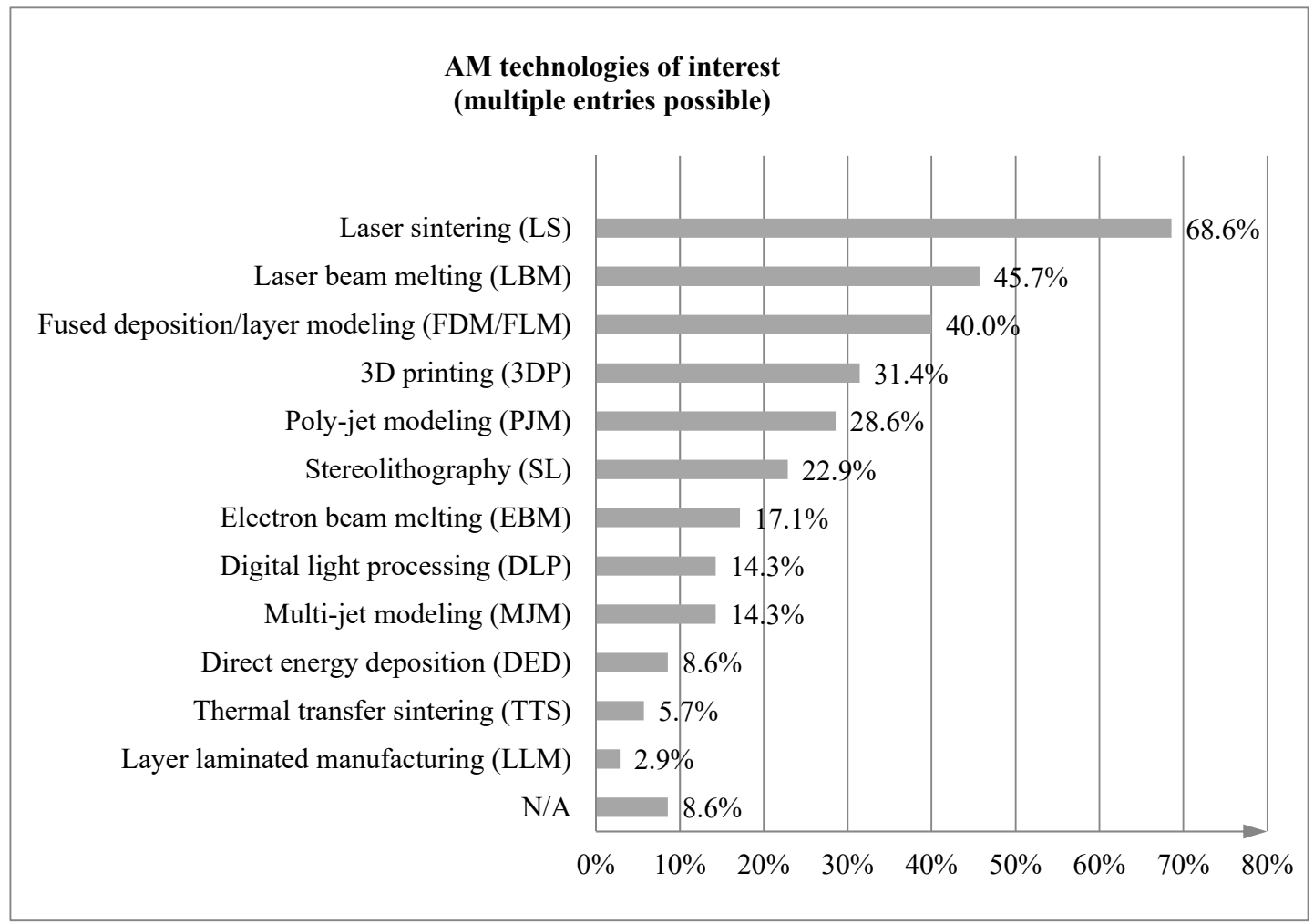

Figure 5. Relevance of the different AM technologies 
The participants were queried on the reasons for their choice of AM technologies of interest and had the option of marking the decisive factors. The incidence of the reasons is shown in Figure 6. One interesting aspect of the result is that costs were not available as a predefined option, as their estimation is affected by several factors, although this factor was notably stated numerous times in the free text field. By contrast, familiarity with the specific AM technology was not seen as a relevant reason for the choice. When asked for the reasons for their decision concerning the relevance of the technologies, the available materials were cited most frequently by the participants, followed by accuracy levels and the possible build volumes of the processes.

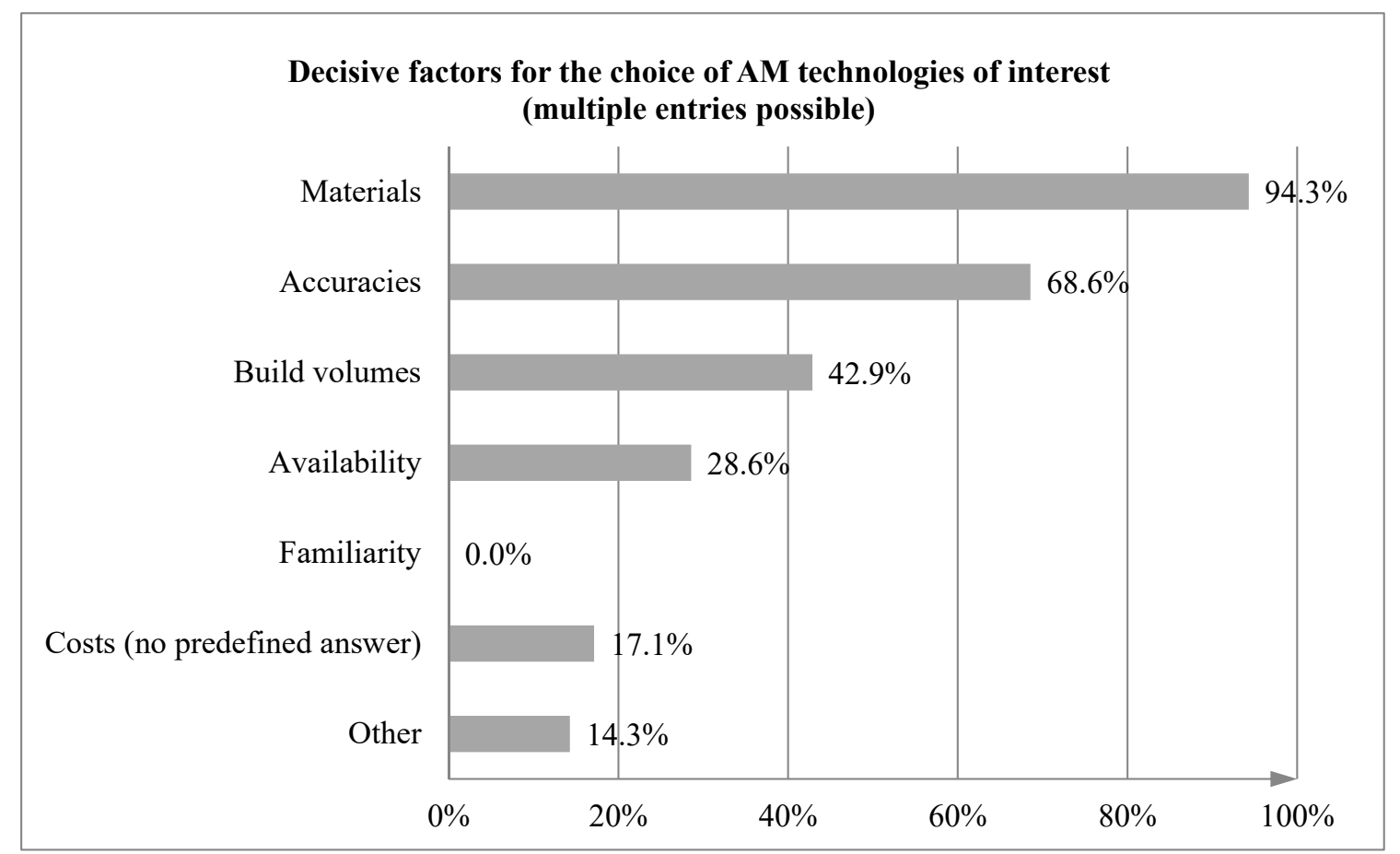

Figure 6. Reasons for the choice of technologies of special interest

The participants' answers regarding the importance of different groups of materials are shown in Figure 7 , including the standard deviation. With the large standard deviation, it can be seen that there is a high divergence in the rating of the importance of the groups of materials, whereby composites are rated as less important than metal and plastic.

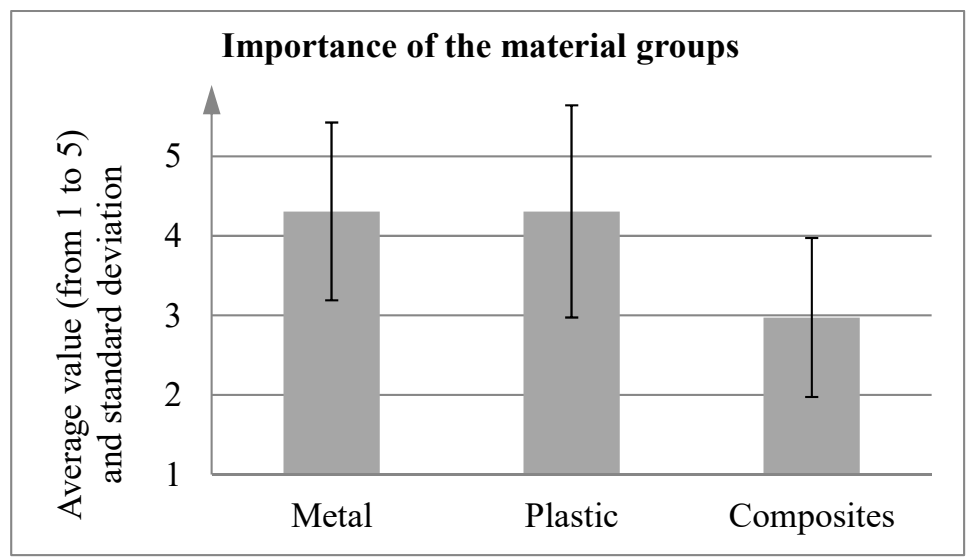

Figure 7. Importance of groups of materials 
With a view to design freedom with AM, the factors of interest to the participants are shown in Figure 8. Of special interest for AM is the option of integrating functions and parts $(74.3 \%)$. The reduction in the number of assembly steps, improvement of performance and the possibility of lightweight design are deemed to be of almost equal importance by the participants (with $62.9 \%$ and $57.1 \%$ respectively). Other aspects cited by the participants are a reduction of cost and time, and hybrid production incorporating conventional manufacturing technologies.

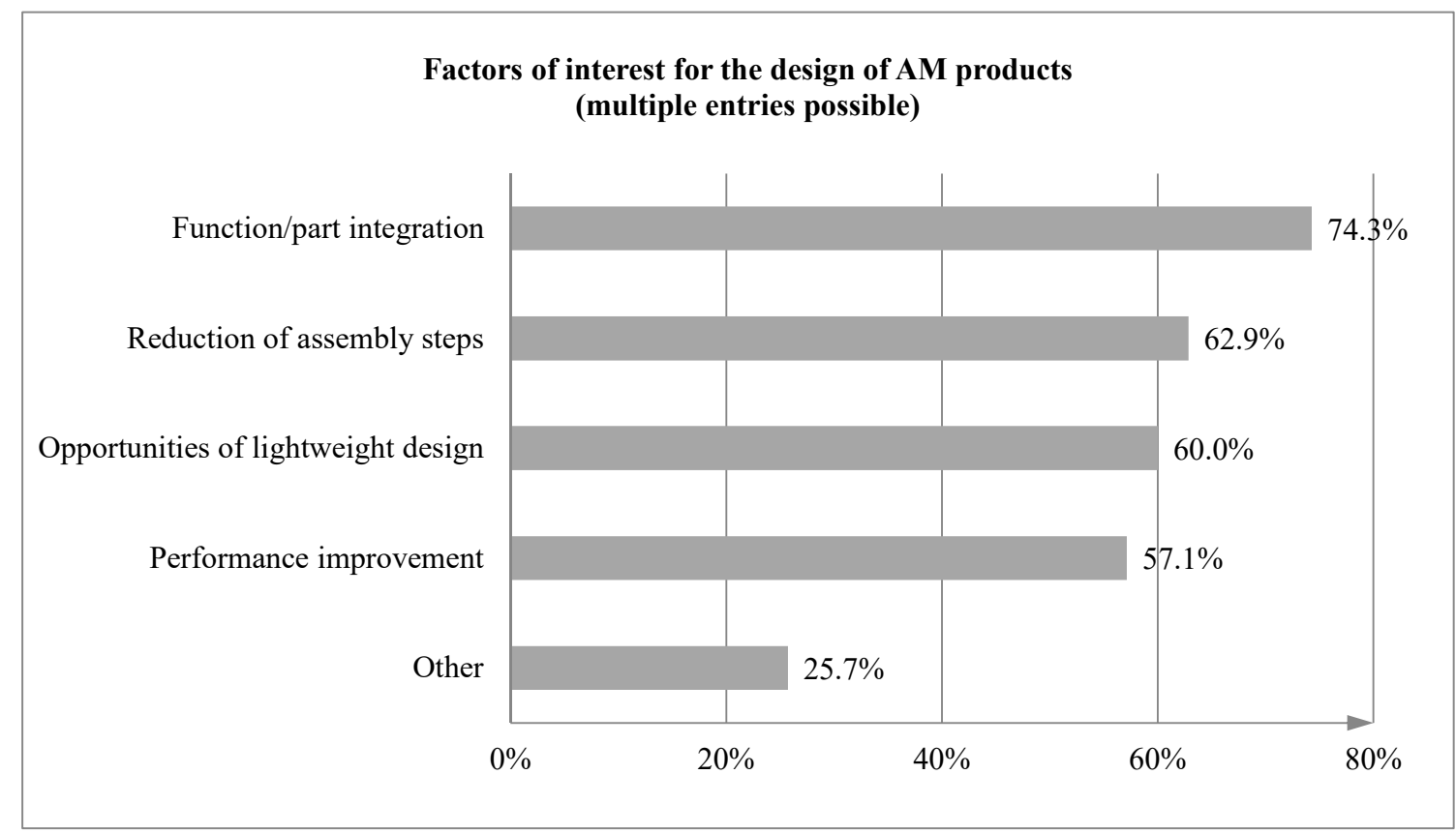

Figure 8. Aspects of interest in the freedom of design with AM

\section{Importance and preparation of the required information for a DfAM}

In this section, the results of the survey concerning the weighting of information in the Internet-based platform are presented. To determine the weighting of the information included in the Internet-based platform from an industrial perspective, questions were asked concerning the importance of possible information for the DfAM. The participants had to rate the importance of information categories by relevance with a view to the development of additively manufactured parts between 1 (not necessary) and 5 (absolutely necessary). The available options were generated according to the reviewed literature (see Section 2.1). The following options were evaluated by the participants:

- Specific manufacturing restrictions for particular AM technologies

- General descriptions of particular AM technologies for generating an understanding of the specific manufacturing restrictions

- Descriptions of data formats and data processes

- Description of an approach for developing additively manufactured parts

- Description of a computer-aided procedure for generating topologically optimized parts

- Examples of good solution principles for additively manufactured parts

- Description of a method for assessing the potential of using AM technologies for a product or product idea

- Description of a method for determining the suitability of AM technologies for a specific application

- Description of legal aspects in the context of AM in terms of liability and property issues

The results of the survey regarding the importance of several information categories and the standard deviation are shown in Figure 9, whereby the available options are listed in the order of their importance 
to the participants. As shown, the standard deviation is not insignificant, and the rating cannot be considered definite. This is due to the inhomogeneous group and the wide range of prior knowledge levels among the participants. However, it can be seen that the assessment of information which is more important on average shows greater consensus and a smaller standard deviation than the information rated as less important overall. Only the two lowest rated aspects have a median of three, according to a Wilcoxon signed-rank test.

In addition to the predefined options, information about the costs of the manufacturing technologies and material properties were declared to be important information for the development of additively manufactured parts.

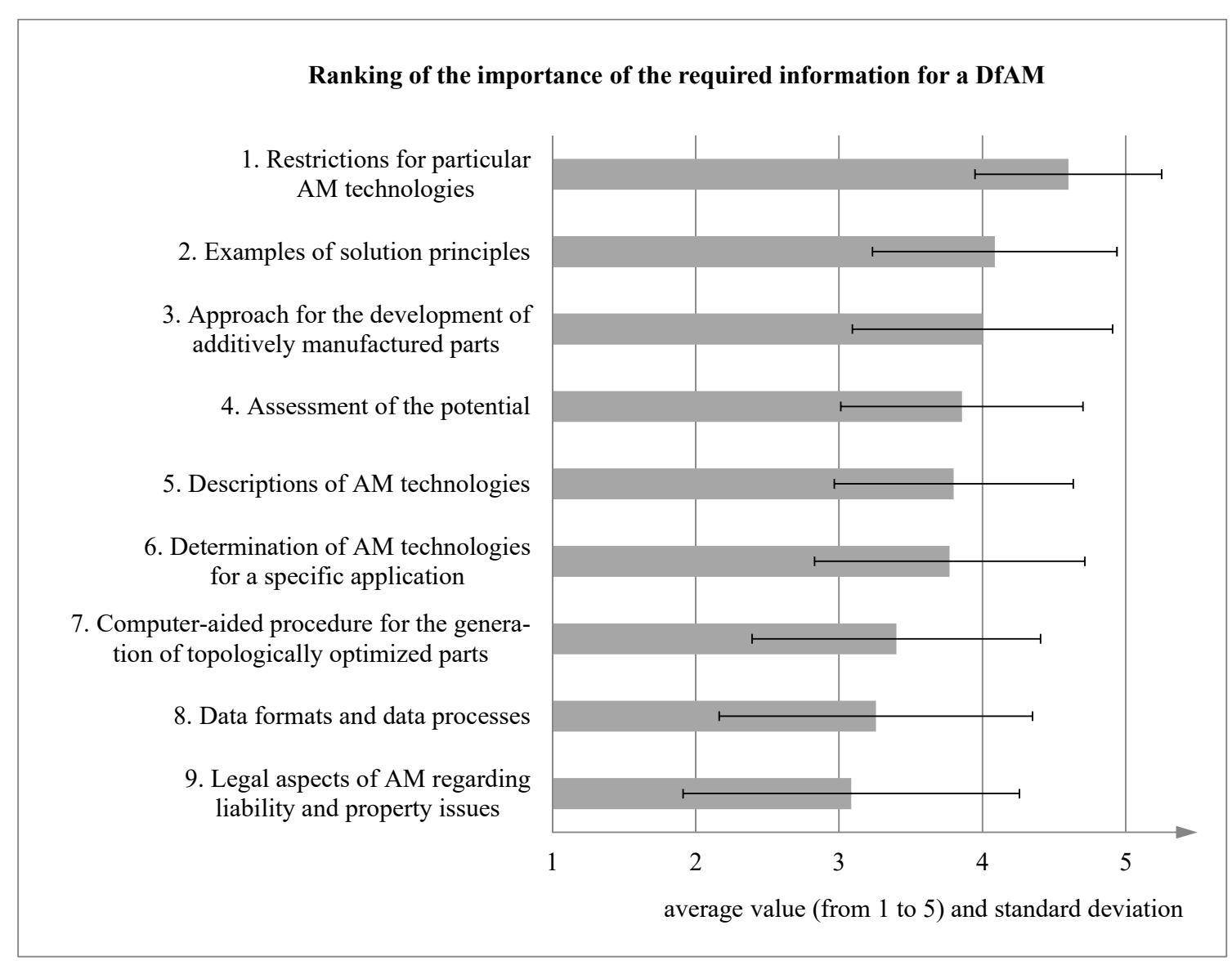

Figure 9. Importance of different information categories for developing AM parts

To assess adequate preparation of the information required for developing additively manufactured parts, the participants of the survey were asked how the information should be prepared. The summarized results are shown in Figure 10 and sorted by relevance. Evidently, characteristics of the preparation that are related to digital presentation of the information are rated especially highly, such as the search functionality, the possibility of filtering the information and the ability to interlink related information. The possibility of enhancing the provided information as a result of the increasing knowledge of AM-specific developments can also be more easily implemented within a digital environment, which goes hand in hand with the rating of the Internet-based preparation of information as being the second most important aspect. In contrast to this, traditional methods of presenting required information for the development of products were rated as being less important, such as the presentation in a paper-based format, a tabular structure within the presentation and the limitation of access for external parties. 


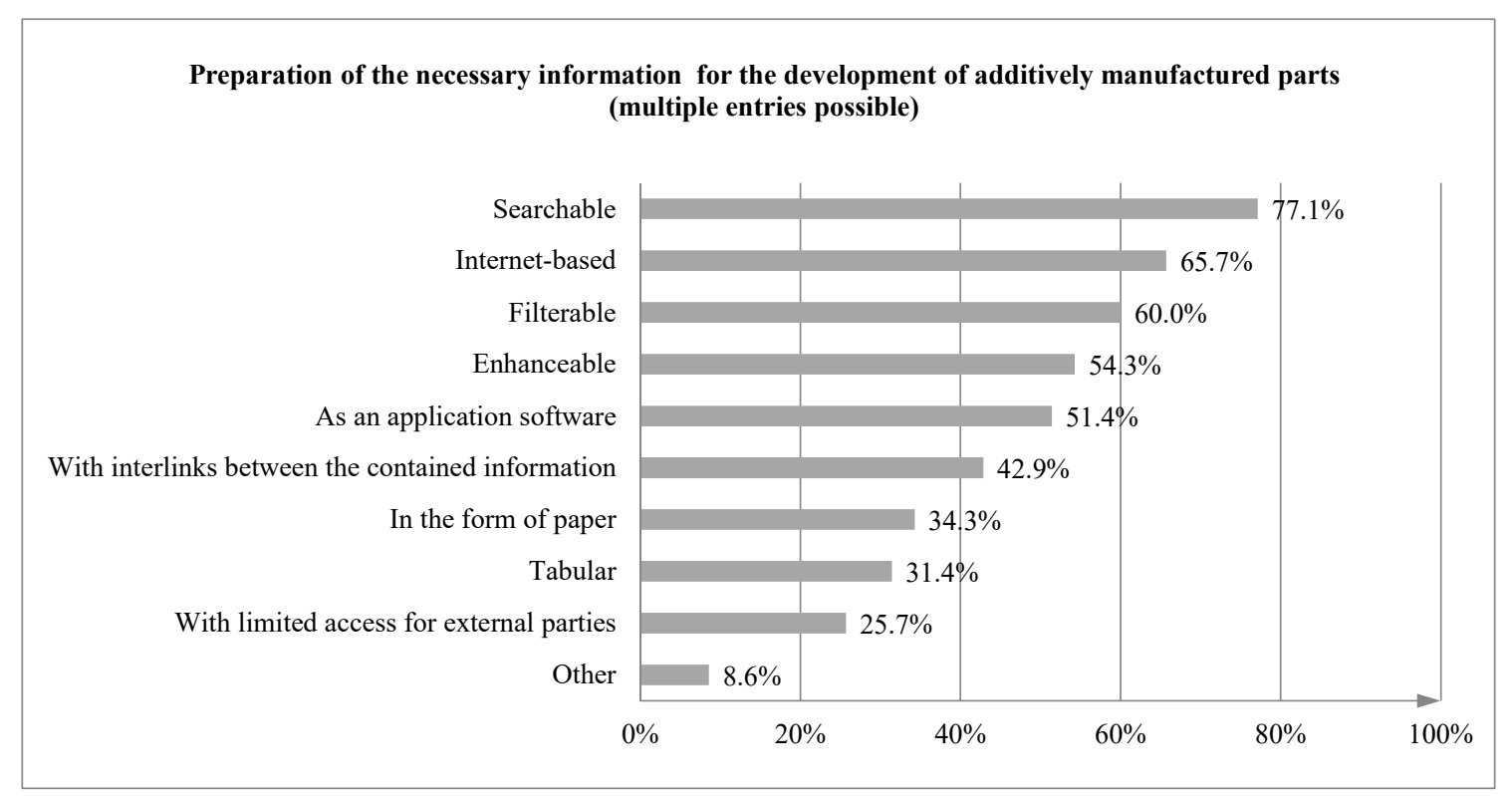

Figure 10. Relevance of potential ways of preparing important information for the development of additively manufactured parts

\section{Realization of an Internet-based information platform for the development of additively manufactured parts based on the survey}

After conducting the presented survey in an industrial environment, an Internet-based platform for the development of additively manufactured parts was created, and the functions rated as being important were realized. The platform's content is based on the rating of the importance of the information required for developing additively manufactured parts, and it is structured according to the timeline within a product-development project.

Access to the platform starts with registration/login. This user management concept was implemented to enable specific users' rights to be controlled in terms of modifying the tool's content. After registration, each user gets a view of an individually selected front page or starts the system with the predefined view of a development process. To structure the information in the Internet-based tool, it is thematically clustered and assigned to the different phases of product development. The underlying description of the development process is, due to its current validity and its guideline character, chosen in accordance with VDI 2221 from 1987, on which the process proposed by Kumke et al. (2016) is also based, for example. In the context of the Internet-based platform, the process is only used as a tool for communicating the various included information categories and can therefore be easily changed.

In further steps, the users can either select the desired information, if they are already familiar with the platform, or they can use the implemented functions of the platform to find it. For easier access to the information at the time that this paper was written, the following functions have been implemented in the platform, and are illustrated in Figure 11:

- Access bar that shows all headings of the platform's included information in the predefined order according to their importance during product development.

- Search function that shows content including the search term and highlights the relevant area within it.

- Links between related content items that enable inexperienced designers to explore the content appropriate to their interests, thus leading to relevant related information.

- Print function that enables designers to extract reoccurring relevant content in a printable format. 


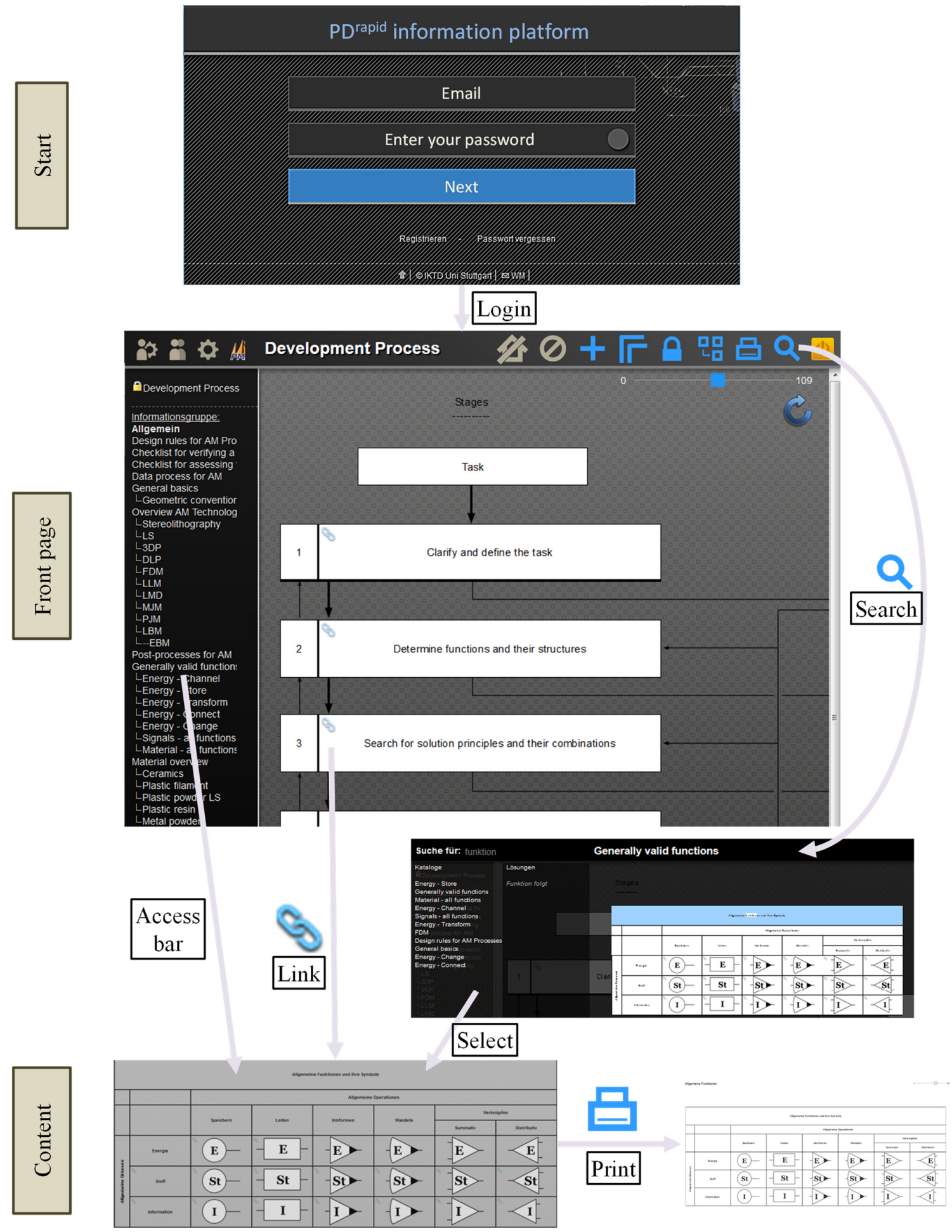

Figure 11. Implemented functions of the platform

When planning development, for instance, information about available AM processes and scenarios for their application are relevant. For example, these may include potential market prospects and general information about the operation principles and potential materials/material properties of specific 
manufacturing technologies. The relevant information can therefore be retrieved by starting at the description of the development process and using the links to this content.

Especially during the early phases of product development, when the most freedom of design is available, a function-oriented support system for designers that takes full advantage of the existing scope of design freedom is required in order to realize a design. This includes information on identifying an appropriate solution principle in order to fulfill the desired function. Information regarding good solution principles in the case of AM is therefore integrated into the platform. It is structured in accordance with generally valid functions according to (Weiss et al., 2016), and can either be explored using the search function, the links or by manually navigating the content using the access bar.

According to the survey presented above, the following information is currently included in the platform:

- General information about the use of the platform

- Restrictions for particular AM technologies

- Examples of solution principles

- Checklist for assessing the potential of using AM technologies for a product or product idea

- General descriptions of AM technologies

- Checklist for verifying a suitable design for additively manufactured parts

- Information on material properties relating to specific AM processes

- Development process for assigning information to the different product development phases

- Description of the data process for AM

- Description of post-processes for AM

As a result of the implemented user management system, users can modify and supplement the content and suggest optimization approaches to the administrators.

\section{Example of a usage scenario for the platform}

In this section, the benefit of using the platform shall be shown in an example scenario that is depicted in Figure 12.

The design task of an adaptive control element is adopted for the use case in question: This is described in more detail in (Weiss et al., 2017). The design task is to develop a human-machine interface (HMI) that changes its shape according to the forces applied to its exterior, so as to enable positive locking for high torque transmission from the hand to the element.

1. After clarifying the task and deciding to potentially use AM technologies for the production of the HMI, the first content on the platform that is used is the checklist for assessing the potential of using AM technologies for a product or product idea. This shows that there may be potential for part integration. AM suits potential personalization, complex shapes could enable ergonomic design, and the build volume and batch size are also small.

2. In the next step, possible solution principles for enabling the movement of single elements of the HMI are explored using the collection of examples for solution principles, and are used to define an initial concept for the HMI's design.

3. With this initial design idea, the general descriptions of AM technologies (3a) can be used to determine appropriate technologies for manufacturing the HMI from plastic. To determine the used AM technology further, the plastic processing technologies are compared by means of their more specific descriptions (3b). Fused deposition modeling (FDM) technology is chosen due to its sufficient accuracy, availability and the availability of materials.

4. In the next step, the design is refined for the production with FDM by recurrently using the information about the restrictions for the specific AM technology (4a) and the checklist for verifying a suitable design for additively manufactured parts (4b).

Later on, the production of the first HMI can be initiated by using the description of the data process for AM. The cycle of continuously improving the HMI can then start. 


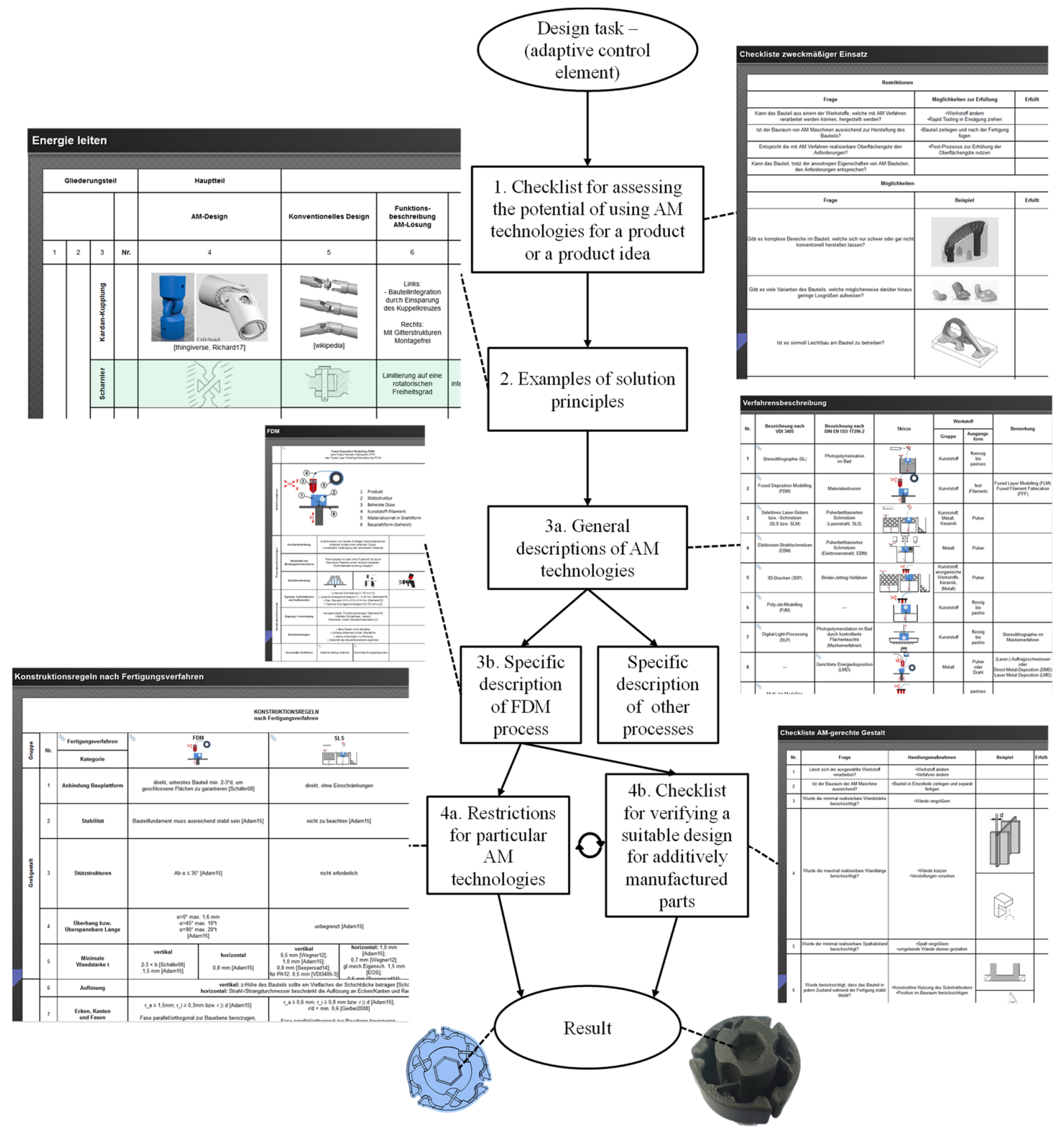

Figure 12. Example usage scenario of the platform

\section{Conclusion and outlook}

In this paper, the results of a survey for the conception of an Internet-based platform for supporting the development of additively manufactured parts are presented, while insights are also given into the final design of the Internet-based platform itself, its content and its functions. The function of the platform was tested as a support evaluation with several persons during its development, and the practical applicability was able to be initially evaluated in two student projects and in initial contact with industry. An evaluation in the form of a long-term development project was not able to be conducted thus far, although this is planned for the future. At the point of this paper's publication, the information contained therein is limited to AM-specific content, and does not include general information about nontechnology-specific methods used during product development. According to the test in an industrial environment, the content should be adapted and supplemented in future. This may be achieved through the use of the user management system and by utilizing users of the platform as creators of new content. 


\section{References}

acatech, Leopoldina and Union der deutschen Akademien der Wissenschaften (2016), Additive Fertigung, München.

Adam, G.A.O. and Zimmer, D. (2014), "Design for Additive Manufacturing-Element transitions and aggregated structures", Journal of Manufacturing Science and Technology, Vol. 7 No. 1, pp. $20-28$. https://doi.org/10.1016/j.cirpj.2013.10.001

Gebhardt, A. and Hötter, J.-S. (2016), Additive manufacturing: 3D printing for prototyping and manufacturing, Hanser Publications, Munich.

Gibson, I., Rosen, D. and Stucker, B. (2015), Additive Manufacturing Technologies. Springer New York. New York, NY. https://doi.org/10.1007/978-1-4939-2113-3

Hague, R., Campbell, I. and Dickens, P. (2005), "Implications on design of rapid manufacturing", Proceedings of the Institution of Mechanical Engineers, Part C: Journal of Mechanical Engineering Science, Vol. 217 No. 1, pp. 25-30. https://doi.org/10.1243/095440603762554587

Hällgren, S., Pejryd, L. and Ekengren, J. (2016), “(Re)Design for Additive Manufacturing”, Procedia CIRP, Vol. 50, pp. 246-251. https://doi.org/10.1016/j.procir.2016.04.150

Kirchner, K. (2011), Entwicklung eines Informationssystems für den effizienten Einsatz generativer Fertigungsverfahren im Produktentwicklungsprozess, $\mathrm{PhD}$ thesis, Technische Universität Braunschweig.

Kumke, M., Watschke, H. and Vietor, T. (2016), "A new methodological framework for design for additive manufacturing", Virtual and Physical Prototyping, Vol. 11 No. 1, pp. 3-19. https://doi.org/10.1080/17452759.2016.1139377

Laverne, F., Segonds, F., Anwer, N. and Le Coq, M. (2014), "DfAM in the design process: a proposal of classification to foster early design stages", Proceedings of the CONFERE 2014, Sibenik, Croatia.

Leutenecker-Twelsiek, B., Klahn, C. and Meboldt, M. (2016), "Considering Part Orientation in Design for Additive Manufacturing”, Procedia CIRP, Vol. 50, pp. 408-413. https://doi.org/10.1016/j.procir.2016.05.016

Mellor, S., Hao, L. and Zhang, D. (2014), "Additive manufacturing. A framework for implementation", International Journal of Production Economics, Vol. 149, pp. 194-201. https://doi.org/10.1016/j.ijpe.2013.07.008

Ponche, R., Kerbrat, O., Mognol, P. and Hascoet, J.-Y. (2014), “A novel methodology of design for Additive Manufacturing applied to Additive Laser Manufacturing process", Robotics and Computer-Integrated Manufacturing, Vol. 30 No. 4, pp. 389-398. https://doi.org/10.1016/j.rcim.2013.12.001

Seepersad, C.C., Allison, J. and Sharpe, C. (2017), "The need for effective design guides in additive manufacturing", Proceedings of the 21st International Conference on Engineering Design (ICED17), Vol. 5: Design for X, Design to X, Vancouver, Canada, August 21-25, 2017, pp. 309-316.

Tang, Y. and Zhao, Y.F. (2016), "A survey of the design methods for additive manufacturing to improve functional performance", Rapid Prototyping Journal, Vol. 22 No.3, pp. 569-590. https://doi.org/10.1108/RPJ-01-20150011

Thompson, M.K., Moroni, G., Vaneker, T., Fadel, G., Campbell, R.I. et al. (2016), "Design for Additive Manufacturing. Trends, opportunities, considerations, and constraints", CIRP Annals - Manufacturing Technology, Vol. 65 No.2, pp. 737-760. https://doi.org/10.1016/j.cirp.2016.05.004

Vayre, B., Vignat, F. and Villeneuve, F. (2012), "Designing for Additive Manufacturing", Procedia CIRP, Vol. 3, pp. 632-637. https://doi.org/10.1016/j.procir.2012.07.108

VDI (1987), VDI 2221 Systematic approach to the design of technical systems and products, VDI.

Weiss, F., Binz, H. and Roth, D. (2016), "Conception of a design catalogue for the development of functionalities with additive manufacturing", Proceedings of NordDesign 2016, Trondheim, Norway, August 10-12, 2016.

Weiss, F., Janny, B., Binz, H., Maier, T. and Roth, D. (2017), "Using additive manufacturing to design adaptive user interfaces - Lessons learned from a DfAM process", Proceedings of the 21st International Conference on Engineering Design (ICED 17), Vancouver, Canada, August 21-25, pp. 101-110.

Yang, S., Tang, Y. and Zhao, Y.F. (2015), "A new part consolidation method to embrace the design freedom of additive manufacturing", Journal of Manufacturing Processes, Vol. 20 No. 3, pp. 444-449. https://doi.org/10.1016/j.jmapro.2015.06.024

Zhu, Z., Pradel, P., Bibb, R. and Moultrie, J. (2017), “A framework for designing end use products for direct manufacturing using additive manufacturing technologies", Proceedings of the 21st International Conference on Engineering Design (ICED17), Vancouver, Canada, August 21-25, 2017, pp. 327-336.

Florian Weiss, Academic Assistant

University of Stuttgart, IKTD

Pfaffenwaldring 9, 70569 Stuttgart, Germany

Email: florian.weiss@iktd.uni-stuttgart.de 